\title{
ENSINO DE HISTÓRIA E CURRÍCULO:
}

\section{RELAÇÕES ENTRE DIRETRIZES, PARÂMETROS, CONTEÚDOS E CONHECIMENTO HISTÓRICO NA SALA DE AULA DE ESCOLAS PÚBLICAS DO ENSINO FUNDAMENTAL. UBERLÂNDIA-MG (2000-2010)}

\author{
HISTORY TEACHING AND CURRICULUM: RELATIONS GUIDELINES, \\ PARAMETERS, CONTENT AND HISTORICAL KNOWLEDGE IN THE CLASSROOM OF \\ PUBLIC SCHOOLS IN THE ELEMENTARY SCHOOL. UBERLÂNDIA-MG (2000-2010)
}

Artur Nogueira Santos e Costa ${ }^{1}$ Regina Ilka Vieira Vasconcelos ${ }^{2}$

RESUMO: Este trabalho apresenta os resultados do projeto de pesquisa "Ensino de História e Currículo: relações entre diretrizes, parâmetros, conteúdos e conhecimento histórico na sala de aula de escolas públicas do Ensino Fundamental. Uberlândia-MG (2000-2010)"; que se dedicou a analisar a organização do currículo de História em escolas públicas de Ensino Fundamental (anos finais) de Uberlândia- MG, ao longo do período 2000-2010. Os principais objetivos concentram-se em conhecer e problematizar processos de seleção de conteúdos para a disciplina de História no Ensino Fundamental em escolas estaduais de Uberlândia, relacionando-os à prática docente e ao cotidiano de escolas públicas.

Palavras-chave: História Social e Escola Pública. Currículo e Ensino de História. Cotidiano Escolar e Conhecimento Histórico.

ABSTRACT: This paper presents results of the research project "History Teaching and Curriculum: relations guidelines, parameters, content and historical knowledge in the classroom of public schools in the elementary school. Uberlândia-MG (2000-2010)", that aims to analyze the organization's of curriculum of history in public schools in elementary school (final year) of Uberlândia -MG, over the period 2000-2010. The main objectives are to meet and discuss procedures for selection of content for the discipline of history in elementary school in state schools in Uberlândia, establishing relationships to teaching practice and daily life in public schools.

Keywords: Social History and Public School; Curriculum and Teaching of History; Daily Life in School and Historical Knowledge.

${ }^{1}$ Graduando em História pela Universidade Federal de Uberlândia. Bolsista de Iniciação Científica do CNPq.

2 Doutora em História Social pela PUC-SP. Professora dos Cursos de Graduação em História e do Programa de Pós-Graduação em História da UFU. 


\section{Introdução}

O ensino de história, no Brasil, no âmbito da educação básica, tem sido objeto de diversas discussões, muitas delas realizadas no seio das universidades públicas. Em grande parte, esses debates apontam questões que se fazem recorrentes no cotidiano dos profissionais da educação básica, dentre as quais destacamos a problemática dos baixos salários, da difícil jornada de trabalho, entre outras. Não queremos, aqui, negar que essas dificuldades existam. No entanto, elas nos lembram uma provocação, feita por Marilena Chauí, sobre o senso comum. Ela nos chamava a atenção para algumas questões que, se olhadas sem cuidado, não são entendidas com precisão. Como exemplo, ela cita a questão de que, a olho nu, o sol parece menor que a terra e que aquele parece girar em torno desta. Sabemos que, na verdade, é o contrário. Utilizando essa linguagem metafórica, Chauí nos alerta para a necessidade de um olhar crítico e pautado pela reflexão (CHAUÍ, 1996, p. 247-248). Abordamos, nesse contexto, essa problematização de Chauí porque esse ciclo de dificuldades pelas quais passam os professores tem sido olhado sem uma visão crítica, tomado como uma certeza a gerar todos os outros problemas da educação. Acreditamos ser necessário investigar um pouco mais a fundo. Para além de constatar que a remuneração paga aos professores é insatisfatória e que suas jornadas de trabalho são consideravelmente grandes, propomos uma reflexão em que seja possível analisar não apenas esses desalentos, mas que nos permita tomar a educação com um processo mais amplo, e, nesse percurso, pensando especificamente no ensino de história, vislumbramos a necessidade de analisar, também, as relações conjunturais que se estabelecem no cotidiano escolar, colocadas em evidência a partir do estudo do currículo.

Nosso foco de trabalho é o currículo de história das escolas públicas de Uberlândia. Sendo assim, consideramos pertinente apresentar a concepção de currículo da qual estamos falando. Para isso, apoiamo-nos nas Diretrizes Curriculares Nacionais para o Ensino Fundamental, aprovadas em 1998, que dizem que 
[...] este conceito [o de Currículo] envolve outros três, quais sejam: currículo formal (planos e propostas pedagógicas), currículo em ação (aquilo que efetivamente acontece nas salas de aula e nas escolas), currículo oculto (o não dito, aquilo que tanto alunos, quanto professores, trazem, carregado de sentidos próprios criando as formas de relacionamento, poder e convivência nas salas de aula). (BRASIL, 1998, p. 6)

Essa informação nos é cara, visto que apresenta uma definição de currículo que perpassa não somente pela ordenação oficial de conteúdos, mas que envolve, também, as experiências de alunos e professores, as tensões político-sociais mantidas no ambiente escolar, etc. Considerando esse conceito, compreendemos que estamos diante de um objeto passível de pesquisa historiográfica, na medida em que o currículo se concretiza a partir das experiências de diversos sujeitos - alunos, professores, especialistas -, colocados em permanentes relações sociais, em um espaço múltiplo: a escola pública.

Temos, nos últimos anos, acompanhado iniciativas de reformulação de currículos, inclusive do de história. Na década de 1980,

\begin{abstract}
em vários estados brasileiros, foram organizadas reestruturações curriculares. Esse momento foi marcado por discussões e debates em torno do ensino de história, os quais giravam, principalmente, sobre novas concepções que deveriam servir de referência para os conteúdos e as metodologias de ensino. O grande marco dessas reformulações concentrou-se na perspectiva de recolocar professores e alunos como sujeitos da História e da produção do conhecimento histórico, enfrentando a forma tradicional de ensino trabalhada na maioria das escolas brasileiras, a qual era centrada na figura do professor como transmissor e na do aluno como receptor passivo do conhecimento histórico. (SCHIMIDT, CAINELLI, 2009, p. 14)
\end{abstract}

Essas reformulações no campo da história, apontadas pelas autoras, são, em parte, resultado das mudanças ocorridas no cenário da historiografia, acompanhadas, de um lado, pelo fortalecimento, no Brasil, da chamada terceira geração da Escola dos Annales, e, de outro, também pela valorização da historiografia inglesa, tendo Edward P. Thompson como um de seus representantes. ${ }^{3}$ Paralelamente a essa movimentação historiográfica,

\footnotetext{
${ }^{3}$ Para maiores informações sobre essas transformações historiográficas, conferir: BURKE, Peter. $A$ escola dos Annales 1929 - 1989: a Revolução Francesa da Historiografia. São Paulo: Editora da Unesp, 2010.
} 
visualizamos algumas conquistas dos profissionais de história, como, por exemplo, a incorporação, nos quadros da ANPUH, dos professores de história da educação básica, o fortalecimento da prática de pesquisa em História, na graduação e na pós-graduação, de modo a assegurar uma formação mais consistente aos historiadores, e, nesse sentido, a tomada do ensino de história como problemática de pesquisa, como tema de investigação. (VASCONCELOS, 2011, p. 32-33)

Esses apontamentos são importantes porque suas consequências refletiram diretamente na organização curricular nas escolas públicas. A primeira linha de questões, com relação às transformações historiográficas, colabora para a preponderância de novas concepções de História, associadas à incorporação de novas problemáticas de pesquisa, o que tende a influir na elaboração de propostas curriculares da área, bem como na atuação de professores na escola pública. A segunda linha, relativa às conquistas, correspondeu à ampliação e ao fortalecimento da formação do profissional de história, e, desse modo, contribuiu para a problematização do ensino de história que havia sendo ensinado nas escolas, direcionada para um esforço de transformá-lo e melhorá-lo, o que requer revisões e reestruturações curriculares.

Retomando essas importantes situações, percebemos que essas questões sobre ensino de história e currículo colocam-se a nós como um desafio necessário, no sentido de considerar a escola pública como campo fértil de investigação, discutindo o que é importante ensinar e, principalmente, com que objetivos.

\section{Material e métodos}

Este trabalho teve seu suporte teórico e metodológico pautado na historiografia, considerando as particularidades do trabalho do historiador, sem, no entanto, desprezar as contribuições de pensadores de outras áreas, como, por exemplo, dos teóricos que se propuseram a refletir sobre o Currículo Escolar. Nesse sentido, as palavras de Michel de Certeau se fazem pertinentes: "em História, tudo começa com o gesto de separar, de reunir, de transformar em 
'documentos' certos objetos distribuídos de outra maneira." (CERTEAU, 1982, p. 81). Certeau nos alerta para o fato de que o historiador, para concretizar seu trabalho, precisa, em primeiro lugar, ter clareza da documentação com a qual irá lidar. Isso nos permite dizer que, em uma pesquisa historiográfica, o primeiro ponto a ser observado é se existem documentos disponíveis para consulta que contemplem a problemática proposta.

Com base nisso, consideramos pertinente apresentar, aqui, a concepção de documento à qual nos referimos. Como sabemos, uma das contribuições da chamada Escola dos Annales baseia-se no alargamento da perspectiva de documentos. Se antes estes eram apenas escritos, de cunho mais oficial, com o advento dos Annales, amplia-se essa visão e o documento passa a ser qualquer material, escrito ou não, que possa apresentar algum vestígio das atividades humanas. Sendo assim, as obras de arte, a literatura, a música, a oralidade, os escritos não oficiais, os registros escolares, entre outros, passam a compor o rol de documentos passíveis de pesquisa. ${ }^{4}$ Outro ponto importante é o alerta de Walter Benjamin, em suas teses "Sobre o conceito de História", em que ele nos falava da importância de "escovar a história a contrapelo" (BENJAMIN, 1985, p. 225). Benjamin, nesse trecho, apontava uma importante questão metodológica: a necessidade de o historiador interrogar suas fontes com um olhar crítico, procurando, ali, o que pode ter sido silenciado, ou o que está nas entrelinhas. Esse é o nosso papel. Sabemos que as fontes não falam por si só, ao contrário, nossas indagações é que direcionam nosso olhar sobre elas.

Feitos esses esclarecimentos, nosso primeiro passo é apresentar, aqui, os documentos selecionados para pesquisa, de acordo com a proposta de trabalho, relacionada à investigação sobre as articulações entre ensino de história e currículo.

O primeiro deles, as Diretrizes Curriculares Nacionais para o Ensino Fundamental, datadas de 1998, tem sua relevância pelo fato de que, durante o período de 2000 a 2010, a estruturação curricular se deu a partir das proposições feitas por esse documento. Nessas diretrizes, pudemos observar a

\footnotetext{
${ }^{4}$ Esta noção de documento baseia-se nas seguintes obras: BLOCH, M. Apologia da história: ou, o ofício de historiador. Rio de Janeiro: Jorge Zahar Ed., 2001. e LE GOFF, J. Documento/monumento. In: Historia e memória. 5 ed. Campinas, SP: Editora da Unicamp, 2003. p. $525-539$.
} 
concepção de currículo a que se referiam, bem como o que foi apontado como importante a ser considerado na estruturação curricular.

Nesse mesmo sentido, selecionamos os Parâmetros Curriculares Nacionais de História - PCNs, produzidos pelo Ministério da Educação, na década de 1990. Este documento apresenta uma proposta de trabalho aos professores de história, em que são discutidos pontos como concepções teórico-metodológicas, avaliação, recursos didáticos e conteúdos a serem ensinados. Da mesma forma que o anterior, nos permite indagar e problematizar a organização dos currículos da área de história, no sentido de entender como essa proposta pode facilitar, ou não, a atividade do professor, bem como compreender o que dele pode ser aproveitado. Cabe ressaltar que os PCNs são de caráter nacional.

Ao lado dos PCNs, julgamos ser pertinente analisar o Conteúdo Básico Curricular - CBC - História, elaborado pela Secretaria de Estado de Educação de Minas Gerais. Assim como os PCNs, o CBC apresenta discussões sobre o sentido da disciplina História, bem como algumas diretrizes para a organização da mesma nas escolas públicas de Minas Gerais.

Nessa mesma esteira, o Guia Nacional de Livros Didáticos, do Programa Nacional de Livros Didáticos, do ensino fundamental - área de História, constituise em um rico material para análise, primeiro porque aponta, em seu início, diferentes questões acerca da organização do ensino de história nas escolas públicas e, em segundo lugar, porque apresenta diversas resenhas de várias coleções de livros didáticos. Não apenas no sentido de conhecer esses livros didáticos, esse documento permite-nos indagar aquilo que tem sido considerado como importante, em termos de conteúdos e abordagens, para ser trabalhado em sala de aula.

Ainda pensando sobre a organização dos currículos, outro conjunto de documentos foi selecionado. Dessa vez, documentos de caráter mais local. Tratase de diversos Projetos Político-Pedagógicos de distintas escolas de Uberlândia. Esse material, pertinente a cada escola, apresenta a maneira como o ensino deve ser organizado naquela instituição, norteando os princípios básicos a serem observados na elaboração do currículo, estabelecendo objetivos para a educação, entre outros aspectos. Nessa mesma linha, alguns Planos Anuais de Curso da área de História foram tomados como material de estudos. Esses documentos 
são, a cada ano, elaborados pelos professores da área, a partir de um conjunto de fatores, como objetivos da disciplina e sua justificativa, processos de avaliação, conteúdos a serem ensinados, etc. Ambos os documentos, que contemplam diversos anos (2001, 2002, 2004, 2006, 2008, 2009, 2010), dãonos suporte para compreender e indagar a dinâmica escolar, problematizando a questão do currículo e do ensino de história.

De acordo com o plano de trabalho proposto, a pesquisa se daria, também, pelo contato com professores e alunos de diferentes escolas de Uberlândia. Nesse sentido, foram elaborados questionários a serem respondidos por professores e alunos. Esses questionários abordam questões pertinentes ao cotidiano escolar, ao currículo, aos objetivos da disciplina e às condições socioeconômicas de cada sujeito envolvido. Essa etapa permite-nos confrontar o que havia sendo proposto pelos documentos às reais condições pelas quais passam os referidos sujeitos.

Acompanhando todo esse processo de seleção e análise de documentos, uma outra etapa esteve sendo realizada. Trata-se da leitura e discussão de bibliografia especializada. Paralelamente à seleção documental, estivemos discutindo textos de historiadores e demais profissionais que problematizaram a questão da pesquisa em história, do currículo, do ensino de história, da escola pública e do cotidiano escolar. Essa etapa é de fundamental importância visto que, além de nos aproximar do que notadamente tem sido produzido nessa área, dava-nos suporte e base para elaborar nossas indagações, fortalecendo a problemática de pesquisa e amadurecendo as perspectivas teóricometodológicas.

\section{Resultados e discussão}

Nossos adolescentes também detestam a História. Votam-Ihe ódio entranhado e dela se vingam sempre que podem, ou decorando o mínimo de conhecimentos que o 'ponto' exige ou se valendo lestamente da 'cola' para passar nos exames. Demos ampla absolvição à juventude. A História como lhes é ensinada é, realmente, odiosa. (MENDES apud NADAI, set. 92/ago. 93, p. 143). 
Esse trecho foi utilizado pela historiadora Elza Nadai, em seu texto sobre os percursos do ensino de História no Brasil. A historiadora, com base nisto, questiona:

Em que medida as questões apontadas são válidas para a juventude e a escola contemporâneas? Terão os estudantes superado a ideia "de que a história como lhes é ensinada é realmente odiosa" e os professores partido para a organização de outras práticas pedagógicas mais significativas? Em que medida discurso e prática se unificam? Para que direção elas apontam? (NADAI, set. 92 / ago. 93, p. 143)

As indagações de Nadai instigam-nos a uma reflexão cujo ponto principal é compreender as configurações do ensino de história nos últimos anos. Os currículos em ação priorizam uma metodologia da História pautada pela simples memorização de fatos? Nossos alunos lançam à História, hoje, um olhar diferente daquele questionado por Nadai? E nossos professores, como organizam suas práticas? Não objetivamos, aqui, dar respostas simplistas para essas questões, contudo, elas se colocam a nós como um desafio necessário, não para diagnosticar um problema, mas para nos conduzir na direção das possibilidades de atuação do professor/historiador na escola pública, enfatizando a relação entre sua atuação em sala de aula e o processo de construção de currículos.

\section{Currículos: concepções e organização}

Neste ponto, retomamos o debate travado por Miguel Gonzáles Arroyo, eu seu texto "Indagações sobre currículo: educandos e educadores: seus direitos e o currículo", em que o autor estabelece uma série de reflexões acerca do currículo e de sua relação com o cotidiano escolar. Na perspectiva de Arroyo,

[...] o currículo, os conteúdos, seu ordenamento e sequenciação, suas hierarquias e cargas horárias são o núcleo fundante e estruturante do cotidiano das escolas, dos tempos e espaços, das relações entre educadores e educandos, da diversificação que se estabelece entre os professores. (ARROYO, 2007, p. 18).

Dessa forma, percebemos que a maneira como o currículo é organizado está diretamente associada às distintas concepções do processo de ensinoaprendizagem e, nesse mesmo encalço, ao posicionamento historiográfico assumido pelo professor. No primeiro caso, a relação existe porque, vejamos, se 
um professor parte do pressuposto de que a aprendizagem se dá por meio da transmissão do conhecimento - método em que o professor sabe todas as coisas e os alunos são meros receptores de informações -, a estruturação do currículo é uma. No entanto, se ele considera que ela se dá a partir da construção do conhecimento, em que o professor é o mediador, e os alunos, com suas diversas experiências, são sujeitos ativos nesse processo, a estruturação é outra. Da mesma forma, um docente cujo posicionamento historiográfico privilegie o estudo dos grandes fatos, dos grandes heróis, em que a história seria, fundamentalmente, a memorização de fatos passados, provavelmente organizaria seu trabalho tendo como foco certos conteúdos, certas metodologias. Um professor que, ao contrário, opte pelo estudo da história atrelada às vivências de seus alunos, em que seu principal objetivo é a reflexão crítica, para além da simples memorização, terá de adotar métodos distintos do primeiro caso, bem como fazer escolhas de conteúdos que fogem do tradicional.

Neste sentido, colocamos mais uma indagação: como nossos professores encaram o currículo? Este é, para eles, apenas uma seleção de conteúdos? Vejamos, por exemplo, o que nos disse uma professora do ensino fundamental, da Escola Estadual Segismundo Pereira, de Uberlândia, quando perguntamos a ela o que seria o currículo e o que deveria ser levado em consideração, quanto aos alunos, para organizá-lo:

O currículo são os conteúdos que devem ser ministrados naquele determinado ano. A escolha e/ou organização são feitas pelo professor, porém com uma pré-definição do MEC. Quanto aos alunos, devem ser considerados o espaço ao qual estão inseridos, idade, conhecimento cultural, ou seja, espaços de vivência. ${ }^{5}$

Como percebemos, e, para nós, é um ponto positivo, a professora tem clareza de que as diversas experiências carregadas pelos alunos, bem como suas faixas etárias, estão diretamente associadas ao sentido que se deve estabelecer ao currículo, na medida em que elas interferem nas relações sociais estabelecidas em sala de aula. Por outro lado, nos perguntamos: esse currículo que, segundo a professora, são os conteúdos, é, de fato, o que é posto em prática no cotidiano? Essa concepção de currículo seria, de acordo com o

\footnotetext{
${ }^{5}$ Entrevista realizada com a professora G. C. M. (que leciona História no Ensino Fundamental, na Escola Estadual Segismundo Pereira, em Uberlândia-MG), no dia 09 de julho de 2012.
} 
conceito estabelecido pelas Diretrizes Curriculares de 1998, apenas o formal, aquele que se refere unicamente às propostas oficiais? São, aqui, provocações. Não com o objetivo de direcionar críticas à professora, mas para nos fazer refletir sobre a complexidade que se lança ao estudo dos currículos, em especial o de história.

Ainda sobre as concepções de currículo adotadas por nossos professores, gostaríamos de discutir mais um ponto. Outra professora da Escola Estadual Segismundo Pereira diz que é "a favor do currículo único na área de história" Este posicionamento nos chama a atenção por alguns fatores. O que seria adotar um currículo único na área de História? Se esta referência diz respeito à escolha, em todas as escolas da rede estadual de Uberlândia, dos mesmos conteúdos a serem trabalhados em cada ano, isso já seria preocupante. No entanto, como já mencionado, o currículo é algo que está além da simples organização conteudista. Miguel Arroyo nos alerta para o perigo de "organizar um currículo único, igual, tendo como parâmetros os alunos tidos como mais capazes." (ARROYO, 2007, p. 30) Nesse sentido, atrelando o que diz a professora à proposição de Arroyo, nossa preocupação vai um pouco mais adiante. Como sabemos, as diversas escolas de Uberlândia possuem alunos com as mais distintas condições socioculturais. Sendo assim, a organização do processo de ensino-aprendizagem deve ser o mesmo em todas as escolas? Acreditamos que isso seria arriscado. Arriscado pelo fato de que na realidade de cada escola, com seus diferentes grupos de alunos, as experiências de vida trazidas por eles, carregadas de significados sociais, não são as mesmas. Se não são as mesmas, a maneira com que cada um consegue se inserir na dinâmica escolar também não é a mesma, logo, o currículo também não é o mesmo.

Com relação aos alunos e como eles encaram a organização curricular, baseamo-nos em cerca de 100 questionários preenchidos por alunos de diferentes séries. Uma das perguntas propostas era: "Você sabe como é feita (e por quem) a seleção de assuntos a serem estudados durante o ano letivo? Comente." Na maioria dos questionários, a resposta foi bem simples: "Não". Em alguns poucos questionários, houve respostas para além dessa, em que os

\footnotetext{
${ }^{6}$ Entrevista realizada com a professora A. B. S. C. (que leciona História no Ensino Fundamental, na Escola Estadual Segismundo Pereira, em Uberlândia-MG), no dia 09 de julho de 2012.
} 
alunos diziam: "acho que é o professor". Esse quadro nos permite entender que nossos alunos, em sua grande maioria, estão alheios ao sentido que é estabelecido aos currículos. Se eles não sabem como é feita essa organização, sabem qual a lógica que a rege? Sabem qual a relevância de se estudar aqueles determinados conteúdos, seguindo aquela determinada ordem? Talvez, se essa situação fosse invertida, o aparente desinteresse pela disciplina também fosse invertido. São, para nós, hipóteses, mas, além disso, são situações sobre as quais é importante ponderar.

\section{Currículos de História: diretrizes, parâmetros e propostas}

Nos diversos debates acerca da elaboração dos currículos de História, temos percebido que muitos de nossos professores sentem-se restringidos pelos diversos documentos elaborados pelo MEC ou pelas Secretarias Estaduais e Municipais de Educação. Segundo argumentam, esses documentos trazem uma proposta já pronta e engessada, que não admite uma flexibilidade. Notamos, também, que eles justificam a ausência do trabalho com temas transversais e inovadores pelo fato de que há a necessidade de cumprir com os conteúdos abordados, por exemplo, nos CBCs (Conteúdo Básico Comum de Minas Gerais). No entanto, a partir da análise de vários desses documentos, notamos que existem diversas aberturas que permitem que o professor construa sua própria proposta, considerando as peculiaridades de sua localidade e de seus alunos.

Nas Diretrizes Curriculares de 1998, é dito que

Ao definir suas propostas pedagógicas, as escolas deverão explicitar o reconhecimento da identidade pessoal dos alunos, professores e outros profissionais e a identidade de cada unidade escolar e de seus respectivos sistemas de ensino. (BRASIL, Diretrizes, 1998, p. 4)

Este trecho citado não se refere exclusivamente à disciplina de História, mas a todos os conteúdos, de uma forma geral. Contudo, ao o analisarmos, considerando nossas necessidades na área de História, percebemos que existe uma fresta que consente com abordagens que fogem do tradicional. A sugestão é bastante clara: se, para construir sua proposta pedagógica, a escola deve levar em conta as identidades pessoais de todos os seus sujeitos, isso requer, 
fundamentalmente, que ela direcione a prática escolar para conteúdos e métodos que se relacionem com as peculiaridades daquela determinada região. Essa movimentação deve ser feita pelo professor. Sendo assim, há, sim, possibilidade de inovação, e de liberdade de criação.

Nesse mesmo contexto, visualizamos, nos PCNs, o seguinte trecho:

[...] os conteúdos são apresentados apenas como sugestões de possibilidades, que não devem ser trabalhadas na sua integridade. O professor pode selecionar alguns temas históricos, alguns procedimentos de estudo e atitudes importantes de serem valorizados de acordo com o diagnóstico que faz dos domínios dos alunos e de acordo com questões contemporâneas pertinente à realidade social, econômica, política e cultural, da localidade onde mora, da sua região, do seu país e do mundo. (BRASIL, PCNs, 1998, $55-56)$

Os PCNs de História compõem um documento que orienta a organização curricular da área de História em todo o Brasil, como já foi esclarecido anteriormente. Nesse fragmento, notamos diversos pontos que podem ser desdobrados a nosso favor. O primeiro deles refere-se ao fato de que a ordem de conteúdos apresentada configura-se como um eixo de sugestões, de possibilidades, no entanto, fica claro que o docente não precisa, e nem tem condições, de cumprir com todos eles.

O segundo ponto requer que o professor, em sua prática, adote procedimentos, conteúdos, temas históricos pertinentes à realidade social em que os alunos se inserem. Isso, por outro lado, permite que o profissional elabore seu próprio plano de trabalho, a partir de um conjunto de fatores que ele mesmo julgue como importantes e que, assim sendo, não tem por objetivo cercear a liberdade de criação, ao contrário, comporta essa atitude.

Outro ponto relaciona-se a algo que consideramos como grande necessidade no ensino de história: a inserção de problemáticas associadas ao presente do aluno, fortalecendo a concepção de que a história é uma disciplina em movimento e que se preocupa com as inter-relações entre passado e presente.

Em uma das entrevistas realizadas, percebemos, na fala de uma professora, um aspecto que se arrola a um desses pontos apresentados pelos PCNs. Segundo a professora, para a estruturação dos currículos de história, 
deve-se considerar o "presente do aluno e o contexto social em que o mesmo se encontra inserido7." A preocupação da professora em considerar as vivências dos alunos está de acordo com o que tinha sido mencionado anteriormente nos PCNs.

Outro documento no qual percebemos a possibilidade de atuação dos professores é o CBC (Conteúdo Básico Comum de História, de Minas Gerais), que apresenta uma estrutura curricular às escolas mineiras. Um dos elementos norteadores dessa proposta diz que "o professor dispõe de metade da carga horária da disciplina para deter-se mais em determinados tópicos obrigatórios e deve-se definir tempo para se trabalhar os tópicos complementares e/ou outras demandas do projeto pedagógico da escola." (MINAS GERAIS, CBC, 2009, p. 11) Nessa esteira, a seleção dos chamados "tópicos complementares" se daria pelo professor, o que, de certa forma, permite que ele insira, ali, questões, problematizações e discussões consideradas por ele como necessárias. Esse documento não se trata, ao menos na teoria, de uma amarra à capacidade inovadora do professor.

Ainda considerando esses documentos citados, os desafios continuam a apresentarem-se a nós. O questionamento de Déa Fenelon, por exemplo, é bastante pertinente: de qual concepção de História estamos falando? (FENELON, 1982 , p. 7) Nesse sentido, a análise desses documentos permite-nos refletir sobre o tipo de História que tem sido proposto. Vejamos:

O que os historiadores nas novas tendências historiográficas têm em comum é o fato de realizarem vários rompimentos com a história positivista e/ou metódica. Dentre esses se assinalam: a negação da ideia de objetividade e de transparência absoluta dos documentos. Estes, enquanto registros das ações e dos ideais dos homens no tempo, só podem servir como evidências para a construção de explicações históricas se devidamente interrogadas pelo historiador a partir de questões do presente. O conhecimento histórico deixa, assim, de ser mera duplicação do real. O conhecimento histórico, embora ancorado no real e com o objetivo de explicá-lo, torna-se uma construção intelectual resultante do diálogo entre categorias conceituais - e evidências; entre estas e a visão de mundo ao qual o historiador se filia. Assinala-se, ainda, o abandono da visão linear da história, passando-se a atentar para as relações de mudança e permanência ao longo do temo, para a existência de múltiplas

\footnotetext{
7 Entrevista realizada com a professora T. C. C. (que leciona História no Ensino Fundamental, na Escola Estadual Leônidas de Castro Serra, em Uberlândia-MG), no dia 06 de julho de 2012.
} 
temporalidades coexistindo num mesmo tempo cronológico; a interdisciplinaridade com as demais ciências sociais, como a antropologia, a sociologia, a geografia, a psicologia, entre outras. Além desses rompimentos, os objetos do conhecimento histórico se deslocaram dos grandes fatos nacionais ou mundiais para a investigação das relações cotidianas, dos grupos excluídos e dos sujeitos sociais construtores da história. (MINAS GERAIS, CBCs, 2010, p. 14).

Esse trecho, retirado do $\mathrm{CBC}$ de Minas Gerais, apresenta-nos importantes reflexões sobre a concepção de História com a qual está lidando. A primeira delas refere-se ao rompimento com a História Metódica, que esteve em voga, principalmente, no século XIX. Notamos que se trata de entender a História como uma disciplina diretamente associada à subjetividade de quem lida com ela, nesse ponto, abandonando qualquer pretensão de produzir um conhecimento neutro, dissociado das inserções sociais do historiador. Cabe ressaltar que, no âmbito escolar, assumir essa condição da História é, como já foi dito, reconhecer que as experiências dos sujeitos que compõem a escola atrelam-se cotidianamente à execução dos currículos. Assinala-se, também, nesse trecho, a noção de que os documentos, que também não são neutros, só podem contribuir para a compreensão da história se devidamente interrogados pelos historiadores, com suas questões condicionadas pelas problemáticas do presente. Percebemos, ainda, que o conhecimento histórico não é a constatação do real, exatamente do que se passou. Trata-se de um conhecimento que se ampara no real e objetiva interpretá-lo, mas que resulta das intersecções entre documentos, historiadores e suas experiências e posicionamentos historiográficos.

Outro ponto que nos chama a atenção é o deslocamento de objetos de estudos. Incluem-se, agora, na história, os grupos excluídos e opta-se por trabalhar com as relações tecidas no cotidiano, abandonando-se o estudo apenas dos grandes fatos, recheados de heróis. Esse último aspecto nos traz uma preocupação: esse deslocamento se projeta, de fato, na seleção de conteúdos a serem estudados? Nesse sentido, ocorreu-nos a fala de uma das professoras entrevistadas, quando discutíamos sobre quais conteúdos é importante ensinar. Ela diz: "acredito que algumas temáticas devem ser mais valorizadas, principalmente aquelas que fogem da história tradicional, que tem como base os 
grandes heróis, a linearidade ${ }^{8}$." A professora complementa dizendo que estes temas aos quais ela se refere são aqueles relacionados ao presente do aluno. Desse modo, acreditamos que o que é dito por ela está em consonância com a discussão estabelecida pelo $C B C$, no sentido de abandonar o estudo da história tradicional, e, dessa forma, optar pela inclusão de temas ligados à vivência do aluno.

Outro importante destaque refere-se ao seguinte trecho dos PCNs:

Novas abordagens iluminam as análises políticas de instituições, de líderes governamentais, de partidos, de lutas sociais e de políticas públicas. Ao mesmo tempo, novos temas sociais e culturais ganham relevância. É o caso de pesquisas destinadas a aprofundar e revelar as dimensões da vida cotidiana de trabalhadores, mulheres, crianças, grupos étnicos, velhos e jovens e das pesquisas que estudam práticas e valores relacionados às festas, à saúde, à doença, ao corpo, à sexualidade, à prisão, à educação, à cidade, ao campo, à natureza e à arte. Nesse propósito, continua sendo utilizada como fonte de pesquisa a documentação escrita e institucional, enquanto são considerados também documentos de diferentes linguagens - textos, imagens, relatos orais, objetos e registros sonoros. (BRASIL, PCNs, 1998, p. 30)

Nesse fragmento dos PCNs, podemos refletir sobre algumas questões que se atrelam ao tipo de história proposto por eles. Assim como o CBC, os PCNs apontam para uma renovação historiográfica. Os temas clássicos de trabalho passaram a ser encarados a partir de novas abordagens, novas perspectivas e temas que antes eram deixados de lado foram arrolados como possibilidades de pesquisa histórica. Inserem-se, aqui, a história das camadas populares, da cultura, das representações, etc. Acompanhando esse movimento, verificamos o alargamento das possibilidades de documentos.

Empreendemos essa discussão a respeito dos posicionamentos historiográficos apresentados pelos $\mathrm{PCNs}$ e pelo CBC porque acreditamos que a organização dos currículos de história articula-se a eles. Não obstante, esses pontos discutidos permite-nos afirmar que estamos trabalhando com uma concepção de história em que os grupos excluídos também participam da construção da história, a partir da atuação de distintos sujeitos, em seus campos sociais, a partir de suas lutas, resistências e conformismos, e também em que os

8 Entrevista realizada com a professora T. C. C. (que leciona História no Ensino Fundamental, na Escola Estadual Leônidas de Castro Serra, em Uberlândia-MG), no dia 06 de julho de 2012. 
diferentes vestígios humanos, escritos e não escritos, são passíveis de pesquisa histórica, na medida em que nos fornecem possibilidades de indagação e entendimento do objeto estudado.

Para além disso, lembramo-nos, ainda, de Paulo Miceli, quando ele diz que

[...] qualquer esforço de renovação do ensino de História depende de uma prática corajosa, [...] parece ser necessário ter coragem de jogar no lixo a comodidade emburrecedora de anotações amarelecidas, repetidas dia após dia, classe após classe, ano após ano. [...] É necessário ter coragem de superar e ignorar programas oficiais, burlar vigilâncias, criar e aceitar novos desafios e experiências. (MICELI, 2011, p. 51)

A fala de Miceli nos faz pensar sobre a atuação de professores e sua relação com os programas oficiais. Ele lembra que qualquer prática inovadora requer o abandono da comodidade, com uma atuação corajosa, no sentido de burlar regras e se propor a criar novas possibilidades. Para isso, é necessário ter clareza de quais objetivos se quer atingir ao ensinar história e, principalmente, considerar o ensino de história como resultado de um esforço conjunto dos sujeitos sociais que lidam com ele.

\section{Projetos Político-Pedagógicos e Planos Anuais de Curso de História para o Ensino Fundamental: proposições, objetivos e conteúdos}

Segundo Conceição CABRINI (et ali), "os alunos reclamam uma história que, para eles, tenha a ver com o seu presente, com a realidade que conhecem mais de perto." (2005, p. 33) Isso, para nós, é uma questão que tem sido amplamente discutida. No entanto, há uma dúvida: como isso tem sido apresentado nos Projetos Político-Pedagógicos das escolas de Uberlândia, e nos Planos Anuais de Curso de História, ensino fundamental, das referidas escolas? Há, nesses documentos, essa preocupação? Além disso, que objetivos esses documentos têm selecionado como importantes?

No Projeto Político-Pedagógico da Escola Estadual Doutor Duarte Pimentel de Ulhôa, para o ano de 2008, observamos:

Os valores, costumes e hábitos da comunidade podem ser conhecidos através do contato diário com os alunos, nas reuniões de 
pais e nos momentos em que estes vêm conversar conosco no dia a dia. E, de acordo com as necessidades e possibilidades, a escola os incorpora à sua proposta pedagógica, lançando mão dos Temas Transversais, tão importantes para a formação do ser humano. (Projeto Político-Pedagógico - E. E. Doutor Duarte Pimentel de Ulhôa, 2008, p. 8).

Incorporar as características da comunidade à proposta pedagógica da escola é uma iniciativa que dá abertura à discussão de assuntos associados ao presente do aluno. Esse possível espaço possibilitado pela escola pode tornar-se uma importante ferramenta à disposição do professor. Uma opção seria aliar a essa abertura uma abordagem que possibilite ao aluno enxergar-se como sujeito da história, entendendo essa disciplina em sua dimensão mais ampla. Todavia, essa proposta deixa dúvidas quanto à sua real força na projeção dos currículos. Por isso, consideramos pertinente cotejá-la com um dos planos de curso da mesma escola. Um desses planos, para o $8^{\circ}$ Ano, elencava, entre seus objetivos:

Estimular a interlocução com questões do presente e de suas relações com a dinâmica de mudanças e permanências dos processos histórico. Os estudantes precisam aprender a questionar a realidade, compreender problemas e resolvê-los. (Plano de Curso Anual, E.E. Dr. Duarte Pimentel de Ulhôa, 2008, p. 5)

Neste plano de curso, também percebemos a preocupação em abordar temas relativos ao presente do aluno. Notamos que o professor selecionou um conjunto de conteúdos ligados à história tradicional, de acordo com a linearidade, porém, esses conteúdos foram permeados por temas transversais ligados às características de comunidade. Além disso, em termos metodológicos, o professor evidência que pretende trabalhar com o conteúdo específico relacionando-o às possíveis abordagens ligadas à inserção social dos alunos.

Outro apontamento resultante de nossas análises refere-se ao seguinte trecho, do Projeto Político-Pedagógico da Escola Estadual Sérgio de Freitas Pacheco:

A escola é uma organização em que os principais fatores de êxito se fundamentam nas crenças, nos valores e nas motivações dos envolvidos nas suas atividades. Sendo a escola um sistema social decorrente de um processo de interação de atores (professores, especialistas, diretores, alunos, pais, etc), cujas relações recíprocas são mutuamente acompanhadas, por um lado, pelas suas características econômicas e, por outro, por um conjunto de 
expectativas, culturalmente estruturadas e compartilhadas pela sociedade [...]. (Projeto Político-Pedagógico da E. E. Sérgio de Freitas Pacheco, 2004, p. 3).

Nesse trecho, notamos importantes pontos que se desdobram com relação aos propósitos de nossa investigação. O primeiro é o reconhecimento de que atividades bem sucedidas na escola são aquelas que contemplam as singularidades de seus sujeitos sociais, com suas distintas vivências. E, nesse mesmo percurso, reconhecer que a escola se compõe pela interação de diferentes "atores", cujas experiências sociais atrelam-se à modelagem da prática escolar é algo que tem sido reclamado por nós há algum tempo, não apenas como diagnóstico, mas como possibilidade de investigação histórica nesse contexto.

Ainda pensando nessa construção da escola pública, conferimos destaque ao fragmento que diz: "É preciso ainda que a educação esteja interligada às rápidas transformações que acontecem em todos os setores do mundo moderno e é importante ter consciência de que toda e qualquer ação não é neutra de significados." (Projeto Político-Pedagógico da E. E. Presidente Tancredo Neves, 2008 , 6) Compreender a escola pública como construção de distintos sujeitos é importante, como já discutido. $E$, nesse trecho, outro destaque se faz relevante: pensar essa construção de sujeitos é pensar os objetivos a que elas se referem. Não se trata de um movimento isento de posicionamentos ideológicos e políticos. Ao contrário, a constituição da escola pública se dá a partir dessa movimentação política e ideológica, em que os distintos sujeitos, alimentados por suas convicções, pretendem alcançar seus diferentes objetivos.

Pensando, agora, mais especificamente, nos conteúdos e objetivos apontados por professores, lembramo-nos mais uma vez dez que diz a equipe de Conceição Cabrini quando esta explica que, frequentemente, encontramos propostas de ensino de história que objetivam apresentar os caminhos da humanidade desde a época das cavernas até os dias de hoje. Trata-se de uma visão de história total, de história de todo mundo. Segundo ela, isso é um risco, porque esse "conteudismo acaba por se expressar em uma sequência meramente cronológica, fragmentada, em uma versão factual, episódica ou mesmo anedótica". (CABRINI et ali., 2005, p. 38) No entanto, complementa: 
Queremos ressaltar que a questão não é tão-somente qual conteúdo de história tratar, mas, sobretudo, como trabalhar esse conteúdo. É preciso que fique claro que, quando dizemos que de seve abandonar as divisões tradicionais da dita história geral (antiga, medieval, moderna e contemporânea), não queremos dizer que não se deva tratar como objeto de estudo nada do que elas abordam. Obviamente, não é questão de se repudiar in totum, e assim tão tranquilamente, todo esse respeitável cabedal de conhecimento produzido em todos esses séculos - o qual é muito importante para todos nós. O que estamos propondo é que você, professor, dê uma volta definitiva de $180^{\circ}$ em relação a essa visão de processo histórico, que constitui o chamado "conteúdo tradicional", que não se preocupe mais em transmitir aos seus alunos toda essa visão sequencial, que não se preocupe em como esgotá-la, pois ela implica uma concepção de história que é preciso ultrapassar. Não queremos dizer que, respeitados os princípios de trabalho que estamos discutindo, você não possa fazer, por exemplo, um produtivo exercício de reflexão histórica com seus alunos, em cima de temas como a educação em Esparta e Atenas, o chamado descobrimento do Brasil, etc, um deles aparentemente bem distante no tempo de seus alunos, e outro, considerado mesmo dos mais tradicionais. (CABRINI et ali., 2005, p. 41-42)

A análise desse trecho de Cabrini propõe-nos um exercício que compreende não apenas a seleção de conteúdos, mas, sobretudo, a reflexão sobre a maneira com que eles vão ser trabalhados e com quais objetivos. Ela alerta para a necessidade de abandonar essa visão de história total, na medida em que é praticamente impossível dominar um conteúdo referente à história do mundo e que isso resultaria em uma simplificação da disciplina, reduzindo-a a simples memorização de fatos, em que não há lugar para a reflexão e autonomia de pensamento. Nesse sentido, indagamos, mais uma vez: como isso pode ser visualizado nas propostas de ensino de nossos professores, em termos de objetivos, conteúdos e abordagens?

Em um Plano Anual de Curso de História para o $9^{\circ}$ Ano do Ensino Fundamental, da Escola Estadual Tubal Vilela da Silva, pudemos perceber a articulação de alguns desses princípios discutidos anteriormente. Segundo consta, os objetivos gerais da disciplina seriam "ampliar a compreensão de sua realidade, especialmente confrontando-a e relacionando-a com outras realidades históricas." (Plano de Curso Anual, E. E. Tubal Vilela da Silva, 2010, 1) Nesse mesmo percurso, elenca como objetivo compreender que as histórias individuais são partes integrantes das histórias coletivas. Como eixo de orientação da abordagem de conteúdos, coloca que ele 
remete para o estudo de questões sociais relacionadas à realidade dos alunos, acontecimentos históricos e suas relações e durações no tempo; discernimento de sujeitos históricos como agentes de transformações e/ou permanências sociais; abordagens históricas e suas aproximações e diferenças; e conceitos históricos e seus contextos. (Plano de Curso Anual, E. E. Tubal Vilela da Silva, 2010, p. 2)

Em termos de metodologia, a professora elaboradora do plano de curso propôs adotar procedimentos que se façam condizentes com as experiências e conhecimentos prévios dos alunos, ressaltando a necessidade de debates, análise de documentos e sistematização do conhecimento. Os conteúdos selecionados perpassam pela discussão sobre a história enquanto disciplina; pela chamada "Era dos Impérios", que compreende o Imperialismo, a Primeira Guerra Mundial e a Revolução Russa; pelo estudo do Brasil República; Segunda Guerra Mundial e Guerra Fria e a Nova Ordem Mundial. Percebemos que o conteúdo, de certa forma, pauta-se pela sequencia cronológica, tradicional e totalizante, mas, como discutido por Conceição Cabrini, isso, por si só, não é o problema. A professora, em diversos pontos, ressaltou sua preocupação em cuidar para que os assuntos trabalhados sejam relacionados às condições dos alunos, priorizando por uma abordagem crítica e que possibilite a reflexão.

Outro plano de curso analisado foi o da Escola Estadual Segismundo Pereira, para o $6^{\circ}$ Ano do Ensino Fundamental, cujos objetivos gerais articulamse em proporcionar ao aluno a compreensão de si mesmo como sujeito histórico, a partir do entendimento do processo histórico como interação entre diversos fatores. Ressalta a necessidade de identificar, em sala de aula, as características sociais, étnico-culturais, atrelando-as à construção dos planos de trabalho. 0 conteúdo selecionado perpassa pela Pré-História e pela Idade Antiga, contemplando as diversas civilizações. Entretanto, a professora preocupa-se em apresentar a necessidade de abordar o conteúdo de forma problematizada, utilizando, como um dos recursos, a análise e discussão de filmes. Essa mesma professora, em entrevista, nos disse: "Considero que todos os conteúdos tem sua importância. Tudo depende da forma como se leciona. A metodologia, é 
fundamental que esteja adequada aos objetivos do aluno e à faixa etária. ${ }^{9 \prime \prime}$ Reforçamos, mais uma vez, que a abordagem, como disse a professora, é o que encaminha um bom trabalho em história.

\section{Considerações finais}

Nossas considerações finais constituem-se muito mais como uma forma de provocação, estimulando a necessidade de sempre repensar a questão do ensino de história, do que de apresentação de conclusões. Para isso, consideremos o seguinte trecho, dito por uma professora da Escola Estadual Segismundo Pereira:

A educação tem como função preparar o indivíduo para o convívio social e para a interação com essa mesma sociedade. A História é a disciplina que o ajuda a compreender as 'inter-relações', 'inter-dependências' e a formar um pensamento crítico. ${ }^{10}$

Essa discussão permite-nos retomar algumas reflexões feitas por Déa Fenelon, quando esta nos falava sobre a importância de que, quando discorremos sobre sociedade, realidade, tenhamos clareza de qual realidade estamos falando. Objetivamos, fundamentalmente, fazer com que nossos alunos compreendam-se como sujeitos ativos na construção da história e, por isso, primamos por um currículo cuja organização estimule cada um deles a se posicionarem como atores de seu presente, e, nesse sentido, uma fala de uma aluna do $8^{\circ}$ ano do Ensino Fundamental, da Escola Estadual Leônidas de Castro Serra, pareceu-nos muito estimulante. Quando perguntamos a ela sobre a relação de sua vida cotidiana com o que ela estudava em História, ela nos disse: "A vida da gente é uma História11". O fato de nossos alunos reconhecerem em suas vidas cotidianas um movimento histórico é algo muito relevante.

Retomamos, ainda,

\footnotetext{
${ }^{9}$ Entrevista realizada com a professora A. B. S. C. (que leciona História no Ensino Fundamental, na Escola Estadual Segismundo Pereira, em Uberlândia-MG), no dia 09 de julho de 2012.

10 Idem.

11 Entrevista realizada com J. M. B., aluna do $8^{\circ}$ ano do Ensino Fundamental, da Escola Estadual Leônidas de Castro Serra, no dia 07 de julho de 2012.
} 
É preciso que iniciemos o aluno no fato de que o conhecimento histórico é algo construído a partir de um procedimento metodológico; em outras palavras, que a história é uma construção. Isso é fundamental para o início da destruição do mito do saber acabado e da história como verdade absoluta. (CABRINI et ali., 2005, p. 43)

Tomamos a abordagem de Cabrini como uma reflexão necessária em nosso campo. Conceber a história como uma construção é algo fundamental, principalmente para que entendamos que se trata de uma disciplina que, por ser uma construção a partir de uma determinada metodologia, está em permanente transformação e, dessa forma, não há, no campo da história, verdades absolutas. Ao contrário, lidamos com possibilidades de discussões, em um contexto social constituído por diferentes sujeitos.

Por fim, mas não com menos importância, trazemos o seguinte trecho, escrito por Déa Fenelon:

Não tenho dúvida de que para fazer avançar qualquer proposta concreta como professores de História [...], temos de assumir a responsabilidade social e política com o momento vivido. Para isto, seria necessário, antes de mais nada, romper com uma maneira tradicional de conceber conhecimento, sua produção e sua transmissão. Isto significa, em primeiro lugar, o posicionamento no presente, para sermos coerentes com a postura de "sujeitos da História". Se queremos avançar nessa perspectiva, temos de nos considerar como "produtores" nessa sociedade que queremos democrática e não como simples repetidores e reprodutores de concepções ultrapassadas. (FENELON, 1982, p. 8)

Tomemos essa proposta como um desafio lançado à nossa profissão: como professores historiadores, faz-se necessário que nos posicionemos no presente como sujeitos ativos na construção da história. Seja na academia, nas escolas, em nosso cotidiano, construímos o conhecimento a partir de nossa interação, da interação entre alunos e professores, da interação entre sujeitos históricos, alimentadas por nossas inserções sociais. Fica, sempre em aberto, o convite para pensarmos, juntos: qual ensino de história queremos? Qual escola pública estamos ajudando a construir? 


\section{Referências}

ANTONACCI, M. A. M.; AQUINO, M. A. de; CARVALHO, A. M. M. Aprender quais histórias? Revista Brasileira de História, São Paulo, v. 7, n. 13, p. 153-164, set. 1986/fev. 1987.

ARROYO, M. G. Indagações sobre currículo: educandos e educadores: seus direitos e o currículo. Brasília: Ministério da Educação, Secretaria de Educação Básica, 2007.

BENJAMIN, W. Sobre o conceito de história. In: - Magia e técnica, arte e política. São Paulo: Brasiliense, p. 222-232.

CABRINI, C. et alii. O ensino de história: revisão urgente. 4. ed. São Paulo: Brasiliense, 2005.

CERTEAU, M. de. A operação historiográfica. In: A escrita da história. Rio de Janeiro: Forense Universitária, 1982, p. 65-119.

CHAUÍ, M. de S. O senso comum. In: Convite à filosofia. 7a ed. São Paulo: Ática, 1996, p. 247-248.

FENELON, D. R. A formação do historiador e a realidade do ensino. Projeto História, São Paulo, n. 2, p. 7-19, ago. 1982.

MICELI, Paulo. Uma pedagogia da história? In: PINSKY, Jaime. $O$ ensino de história e a criação do fato. São Paulo: Contexto, 2011.

NADAI, Elza. O ensino de história no Brasil: trajetória e perspectiva. Revista Brasileira de História, São Paulo, v. 13, n. 25/26, p. 143-162, set. 1992/ago. 1993.

VASCONCELOS, Regina Ilka Vieira. Indagações sobre o lugar da escola pública na produção do conhecimento histórico. In: CARDOSO, Heloisa Helena Pacheco; PATRIOTA, Rosângela. (Org.). Escritas e narrativas históricas na contemporaneidade. Belo Horizonte: Fino Trato, 2011, p. 31-40.

\section{Fontes de pesquisa}

BRASIL. Ministério da Educação. Conselho Nacional de Educação. Câmara de Educação Básica. Parecer CEB n.4/98. Diretrizes Curriculares Nacionais para o Ensino Fundamental. Brasília, DF: MEC/SEB, 1998.

BRASIL. Ministério da Educação. Guia de livros didáticos PNLD 2008. História. Brasília: Ministério da Educação, Secretaria de Educação Básica, 2007. 124 p. (Anos Finais do Ensino Fundamental)

BRASIL. Ministério da Educação. Parâmetros Curriculares Nacionais: História. Brasília: Ministério da Educação, Secretaria de Educação Fundamental, 1998.

MINAS GERAIS. Secretaria de Estado de Educação de Minas Gerais. Conteúdo Básico Comum - CBC. Conteúdos Básicos Curriculares de História do Ensino Fundamental. Belo Horizonte: SEE, 2005. 
Projetos político-pedagógicos das escolas estaduais selecionadas durante a pesquisa.

Planos de curso de professores das escolas estaduais selecionadas durante a pesquisa.

Entrevistas realizadas com professores de Ensino Fundamental (séries finais) em escolas estaduais.

Entrevistas realizadas com alunos de Ensino Fundamental (séries finais) em escolas estaduais. 